(OPEN ACCESS
For numbered affiliations see end of article.

\section{Correspondence to} Dr Jon D Emery, Department of General Practice and Centre for Cancer Research, University of Melbourne, Melbourne, VIC 3010, Australia;

jon.emery@unimelb.edu.au

Received 5 September 2018 Revised 26 November 2018 Accepted 3 December 2018 Published Online First 10 January 2019

\section{SLinked}

- http://dx.doi.org/10.1136/ thoraxjnl-2018-212927

Check for updates

(C) Author(s) (or their employer(s)) 2019. Re-use permitted under CC BY-NC. No commercial re-use. See rights and permissions. Published by BMJ.

To cite: Emery JD, Murray SR, Walter FM, et al. Thorax

2019:74:362-370.

\title{
The Chest Australia Trial: a randomised controlled trial of an intervention to increase consultation rates in smokers at risk of lung cancer
}

\author{
Jon D Emery, ${ }^{1,2,3}$ Sonya R Murray, ${ }^{2}$ Fiona M Walter, ${ }^{1,2,3}$ Andrew Martin ${ }^{4}$ \\ Stephen Goodall, ${ }^{5}$ Danielle Mazza, ${ }^{6}$ Emily Habgood ${ }_{1}{ }^{1}$ Yvonne Kutzer, ${ }^{2,7}$ \\ David John Barnes, ${ }^{8,9}$ Peter Murchie ${ }^{10}$
}

\section{ABSTRACT \\ Background International research has focused on} screening and mass media campaigns to promote earlier patient presentation and detect lung cancer earlier. This trial tested the effect of a behavioural intervention in people at increased risk of lung cancer on help-seeking for respiratory symptoms.

Methods Parallel, individually randomised controlled trial. Eligible participants were long-term smokers with at least 20 pack-years, aged 55 and above. The CHEST intervention entailed a consultation to discuss and implement a self-help manual, followed by selfmonitoring reminders to encourage help-seeking for respiratory symptoms. The control group received a brief discussion about lung health. Both groups had baseline spirometry. Telephone randomisation was conducted, 1:1, stratified Medical Research Council (MRC) dyspnoea score and general practice. Participants could not be blinded; data extraction and statistical analyses were performed blinded to group assignment. The primary outcome was respiratory consultation rates.

Results We randomised 551 participants (274 intervention, 277 control) from whom the primary outcome was determined for 542 (269 intervention, 273 control). There was a $40 \%$ relative increase in respiratory consultations in the intervention group: (adjusted rates $(95 \% \mathrm{Cl})$ intervention $0.57(0.47$ to 0.70$)$, control $0.41(0.32$ to 0.52$)$, relative rate 1.40 (1.08 to 1.82$)$; $p=0.0123)$. There were no significant differences in time to first respiratory consultation, total consultation rates or measures of psychological harm. The incremental costeffectiveness ratio was $\$ A 1289$ per additional respiratory consultation.

Conclusions A behavioural intervention can significantly increase consulting for respiratory symptoms in patients at increased risk of lung cancer. This intervention could have an important role in primary care as part of a broader approach to improve respiratory health in patients at higher risk.

Trial registration number Australian New Zealand Clinical Trial Registry (1261300039 3752). This was registered pre-results.

\section{INTRODUCTION}

Lung cancer is the most common cancer worldwide and most common cause of cancer deaths. ${ }^{1}$ In Australia, there will be an estimated 12741 new cases and 9198 deaths due to lung cancer in

\section{Key messages}

What is the key question?

- Can a behavioural intervention, delivered in primary care, to patients at increased risk of lung cancer increase consulting for respiratory symptoms as an approach to reducing time to diagnose lung cancer?

What is the bottom line?

- The CHEST intervention significantly increased respiratory consultation rates in this population without causing psychological harm, but there was no significant reduction in time to first presentation.

Why read on?

- This is the largest trial to date to test a tailored behavioural approach to reduce diagnostic delay for lung cancer. This targeted approach could be an alternative to mass media symptom awareness campaigns and support early intervention to improve respiratory health in long-term smokers in primary care.

$2018 .^{2}$ Although there have been recent improvements in outcomes for lung cancer, 5-year survival in Australia is only $16 \%{ }^{2}$ and less than $10 \%$ in the UK. $^{3}$ This is primarily because most patients are diagnosed when curative surgical treatment is not possible. ${ }^{34}$

There is growing evidence that time to diagnosis in symptomatic patients is associated with clinical outcomes for lung cancer. ${ }^{5}$ Patient presentation to healthcare and initial management in primary care are key determinants of outcomes of patients with cancer. ${ }^{7}$ The Model of Pathways to Treatment describes symptom appraisal and help-seeking intervals as key timepoints along the cancer diagnostic pathway which contribute to overall time to diagnosis. ${ }^{89}$ Several studies have explored symptom appraisal and help-seeking in people recently diagnosed with lung cancer, identifying factors contributing to later presentation to healthcare. These include limited awareness of cancer symptoms, fear of cancer, ${ }^{10}$ concerns about wasting their own and general practitioners (GPs)' time, ${ }^{11}$ stoicism $^{12}{ }^{13}$ and stigma around smoking. ${ }^{14}{ }^{15}$ Current smokers are 
more likely to experience respiratory symptoms but less likely to consult about them. ${ }^{16}$ Studies in rural Western Australia have found that normalisation of respiratory symptoms is common, especially in those with respiratory comorbidities, with median patient delays to seek help of 50-80 days. ${ }^{1718}$ These times should be compared with lung cancer median volume doubling times of 98 days suggesting such delays could be clinically significant. ${ }^{19}$

The US National Lung Cancer Screening Trial found a 20\% relative reduction in lung cancer mortality from annual low-dose $\mathrm{CT},{ }^{20}$ but the limited cost-effectiveness ${ }^{21}$ and feasibility of implementing national lung cancer screening programmes ${ }^{22}$ means that other approaches to timely diagnosis of lung cancer are needed. The search for useful biomarkers of lung cancer shows promise, but is still at the validation stage. ${ }^{23}$ An alternative strategy is to attempt to diagnose lung cancer earlier through prompt recognition and investigation of symptoms suggestive of the disease, particularly in those at higher risk of lung cancer.

Mass media campaigns to raise symptom awareness have shown variable evidence of effect. Data from the 'Be Clear on Cancer' campaigns in England, have suggested potentially useful short-term effects including increased presentations to general practice and detection of earlier stage lung cancer, but these are based on comparisons with historical control data. ${ }^{24} \mathrm{~A}$ trial in rural Western Australia of a mass media campaign, which included lung cancer symptom awareness, failed to demonstrate an effect on time of presentation to healthcare or time to diagnosis. ${ }^{17}$

Instead of mass media approaches, more targeted interventions could promote earlier presentation to healthcare in individuals at increased risk of lung cancer. The CHEST Trial in Scotland was the first to show preliminary evidence that this approach could alter overall consulting patterns in this population. ${ }^{25}$ In that trial, a theoretically based intervention delivered in primary care to patients at increased risk of lung cancer significantly increased the overall consultation rate by $15 \%$; it was not powered to detect differences in respiratory consultations.

We have adapted the Scottish CHEST intervention for an Australian population. While maintaining its core theoretical elements, we modified the language and format of the self-help manual and expanded approaches to prompt symptom monitoring. We report the results of the CHEST Australia Trial which aimed to test the modified CHEST Intervention in an Australian primary care population and measure its effect on consultation rates for respiratory symptoms.

\section{METHODS}

As we have published the trial protocol, ${ }^{26}$ we report the methods here in brief.

\section{Trial design}

Individually randomised controlled trial conducted in 11 general practices in Perth, Western Australia, and 6 in Melbourne, Victoria, Australia.

\section{Participants}

Eligible participants were long-term smokers with at least 20 pack-years, aged 55 and above, including ex-smokers if their cessation date was less than 15 years ago. Participants were able to read and write English and give informed consent. Exclusion criteria included severe psychiatric or cognitive disorder or previous diagnosis of lung cancer.

Patients who potentially met eligibility criteria were identified from the general practice electronic medical record using the
Canning data extraction software (www.canningtool.com.au). They were invited to participate in the study by letter from their general practice. Invitations included a patient information sheet and expression of interest form, which included four screening questions to assess smoking pack-years. Non-responders were followed up after 2 weeks with a reminder postcard. Eligible patients returning an expression of interest form were followed up by telephone to make a trial appointment at their general practice. Randomisation was performed after completion of baseline data and written informed consent had been obtained.

\section{Intervention}

A trained researcher performed spirometry and then guided the participant through a self-help manual, entitled Chest Symptoms that Call for Action. ${ }^{27}$ The key objectives of the manual were to: increase the salience and personal relevance of symptoms, improve knowledge of symptoms by introducing chest disease prototypes, reinforce the benefits of early intervention in lung cancer and other chest disease, and sanction early consultation. 'If-then' action plans were developed with the participant, linked to symptom checklists, and 'If-then' coping plans discussed to tackle barriers to consultation. A range of monthly prompts to monitor current symptoms were tailored to individual preferences, including SMS and email reminders, postcards, phone calls and fridge magnets.

\section{Control}

A trained researcher performed spirometry and then had a brief general discussion about lung health. This was designed as an attention control and to increase overall engagement in the trial for control participants. Participants then received usual care at their general practice.

In both trial groups, the results of the spirometry were sent to the participant's GP for follow-up according to usual practice.

\section{Outcomes and measures}

The primary outcome of this trial was consultation rates for respiratory symptoms. Data on consultations in the year before the trial and for 12 months after the consultation were collected through audit of GP records. This was a phase II trial of a complex intervention ${ }^{28}$; our outcomes were designed to test whether the intervention has the potential to facilitate the early detection of lung cancer by evaluating its effect across a range of intermediate endpoints.

\section{Additional measures included}

1. Demographics and clinical variables: age, gender, marital status, postcode, highest education level, occupation, Medical Research Council (MRC) Dyspnoea Scale ${ }^{29}$ and lung function at baseline only.

2. Self-efficacy for consulting without delay: a 10-item self-completed scale summed to score $10-100 .^{25}$

3. Knowledge of symptoms of lung disease: a 21-item self-completed checklist of possible symptoms expressed as a percentage correctly selected as associated with chest disease. ${ }^{25}$

4. Symptom appraisal and help-seeking intervals measured using the SYMPTOM instrument (lung cancer version), a self-completed questionnaire that obtains data on presenting symptoms and their duration prior to consultation. ${ }^{30}$ Monthly electronic searches of the GP medical records identified recent respiratory consultations. Participants were sent a SYMPTOM questionnaire to complete about symptoms relating to that consultation. 


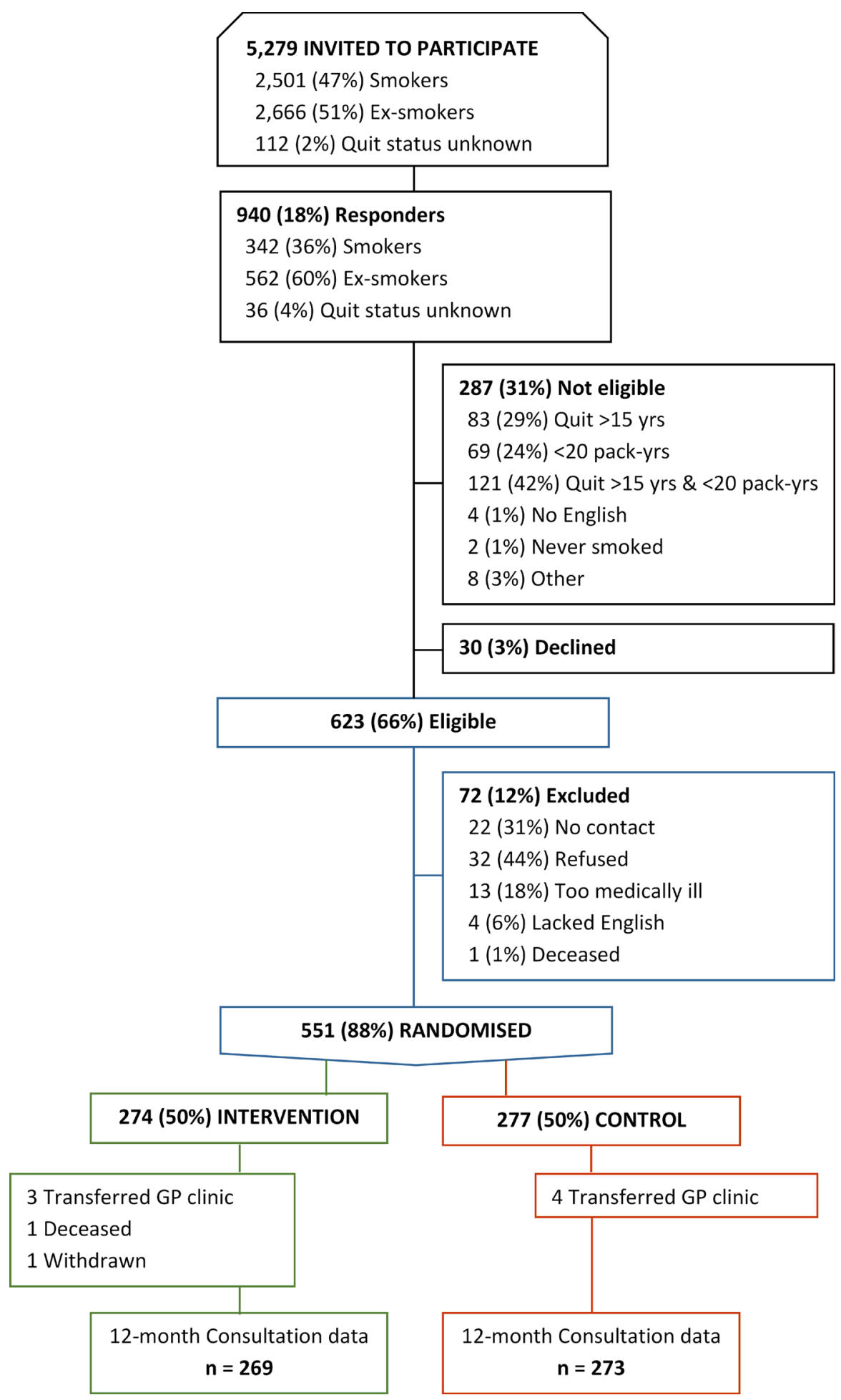

Figure 1 Trial flow chart. GP, general practitioner.

5. Hospital Anxiety and Depression Scale (HADS). ${ }^{31}$

6. Cancer-worry scale: a 6-item self-completed scale, adapted from the breast cancer worry scale and validated in the Scottish CHEST Trial. ${ }^{25} 32$

7. Quality of life using the Assessment of Quality of Life (AQoL-8D). ${ }^{33}$

8. Heath service utilisation: in addition to the primary measure of consultation rates for respiratory symptoms, total general practice consultation rates, chest X-ray requests and referrals to respiratory physicians were captured through audit of general practice medical records. Participants consented to access to their Medicare claims data (Pharmaceutical Benefits Scheme (PBS) and Medicare Benefits Schedule (MBS)) obtained from the Department of Human Services. Medicare is the publicly funded universal healthcare system in Australia. Claims data provided more complete information about visits to other general practices, including prescribing, investigations and referrals arising from these.

Participant-completed measures were collected at baseline, 1 and 12 months, with the exception of the SYMPTOM 
Table 1 Baseline characteristics

\begin{tabular}{|c|c|c|c|}
\hline Characteristic & Level & Intervention $(\mathrm{N}=274)$ & $\begin{array}{l}\text { Control } \\
(\mathrm{N}=277)\end{array}$ \\
\hline Age: mean (SD) (n) & & $64.38(9.8)(274)$ & $64.07(10.64)(277)$ \\
\hline \multirow[t]{2}{*}{ Sex } & Female & $117(42.7 \%)$ & $114(41.2 \%)$ \\
\hline & Male & $157(57.3 \%)$ & $163(58.8 \%)$ \\
\hline FEV1: mean (SD) (n) & & $80.90(21.65)(273)$ & $81.63(20.51)(276)$ \\
\hline Smoking pack-years: mean (SD) (n) & & $45.18(23.84)(274)$ & $45.99(24.4)(277)$ \\
\hline \multirow[t]{2}{*}{ Smoking status } & Ex-smoker & $168(61.3 \%)$ & $148(53.4 \%)$ \\
\hline & Current & $106(38.7 \%)$ & $129(46.6 \%)$ \\
\hline \multirow[t]{5}{*}{ Comorbidities } & Cardiovascular & $100(36.5 \%)$ & $115(41.5 \%)$ \\
\hline & Respiratory & $90(32.8 \%)$ & $89(32.1 \%)$ \\
\hline & Psychiatric & $44(16.1 \%)$ & $41(14.8 \%)$ \\
\hline & Diabetes & $28(10.2 \%)$ & $35(12.6 \%)$ \\
\hline & Other & $92(33.6 \%)$ & $92(33.2 \%)$ \\
\hline Respiratory consultations from 12 months to baseline: mean (SD) (n) & & $0.86(1.62)(269)$ & $0.76(1.25)(273)$ \\
\hline All consultations from 12 months to baseline: mean (SD) (n) & & $9.06(7.49)(270)$ & $9.11(7.70)(273)$ \\
\hline \multirow[t]{4}{*}{ Accommodation } & Own your home & $204(74.5 \%)$ & $212(76.5 \%)$ \\
\hline & Rent your home & $50(18.2 \%)$ & $33(11.9 \%)$ \\
\hline & Other (please specify below) & $20(7.3 \%)$ & $22(7.9 \%)$ \\
\hline & Missing & 0 & $10(3.6 \%)$ \\
\hline \multirow[t]{8}{*}{ Education } & Year 11 or below & $86(31.4 \%)$ & $89(32.1 \%)$ \\
\hline & Year 12 or equivalent & $40(14.6 \%)$ & $38(13.7 \%)$ \\
\hline & Trade/apprenticeship & $29(10.6 \%)$ & $39(14.1 \%)$ \\
\hline & Tertiary certificate/diploma & $49(17.9 \%)$ & $57(20.6 \%)$ \\
\hline & Undergraduate university degree & $24(8.8 \%)$ & $17(6.1 \%)$ \\
\hline & Postgraduate university degree & $17(6.2 \%)$ & $12(4.3 \%)$ \\
\hline & Other (please specify) & $26(9.5 \%)$ & $17(6.1 \%)$ \\
\hline & Missing & $3(1.1 \%)$ & $8(2.9 \%)$ \\
\hline \multirow[t]{5}{*}{ Living arrangements } & On your own & $70(25.5 \%)$ & $70(25.3 \%)$ \\
\hline & With a partner/spouse & $166(60.6 \%)$ & $166(59.9 \%)$ \\
\hline & With other family & $32(11.7 \%)$ & $28(10.1 \%)$ \\
\hline & Other (please specify below) & $6(2.2 \%)$ & $5(1.8 \%)$ \\
\hline & Missing & 0 & $8(2.9 \%)$ \\
\hline \multirow[t]{7}{*}{ Occupation (more than one can apply) } & Retired & $85(31.0 \%)$ & $98(35.4 \%)$ \\
\hline & Caring for dependent relative & $14(5.1 \%)$ & $16(5.8 \%)$ \\
\hline & Voluntary worker & $20(7.3 \%)$ & $14(5.1 \%)$ \\
\hline & Unemployed & $52(19.0 \%)$ & $63(22.7 \%)$ \\
\hline & Student & $8(2.9 \%)$ & $3(1.1 \%)$ \\
\hline & Looking after home/family & $43(15.7 \%)$ & $48(17.3 \%)$ \\
\hline & Disabled/unable to work & $21(7.7 \%)$ & $22(7.9 \%)$ \\
\hline
\end{tabular}

instrument as already described. Health service utilisation data were collected at 12 months from an audit of general practice medical records and obtaining Medicare claims data.

\section{Sample size}

Data from the Scottish trial was used to inform power calculations. ${ }^{25}$ Assuming that the primary endpoint of consultations for respiratory symptoms follows a Poisson distribution, and that the expected average rate over 12 months in the study population would be 1.06 for control patients and 25\% higher for intervention patients, a sample of 534 would provide at least $80 \%$ power to reject the null hypothesis of no difference between the groups at the two-sided 5\% level of significance. Accounting for the same attrition rate observed in the Scottish CHEST trial, we required a total sample of 550 participants.

\section{Randomisation}

Those who met the eligibility criteria and who consented to participate were randomised 1:1 to either the control or intervention. Randomisation was performed using a centralised independent telerandomisation system managed by the National Health and Medical Research Council (NHMRC) Clinical Trials 


\begin{tabular}{|c|c|c|c|}
\hline Characteristic & Level & $\begin{array}{l}\text { Intervention } \\
(\mathrm{N}=274)\end{array}$ & $\begin{array}{l}\text { Control } \\
(\mathrm{N}=277)\end{array}$ \\
\hline $\begin{array}{l}\text { Mean respiratory } \\
\text { consultations during } \\
\text { 12-month follow-up } \\
\text { (SD) (n) }\end{array}$ & & $0.67(1.01)(269)$ & $0.47(0.78)(273)$ \\
\hline \multirow[t]{8}{*}{$\begin{array}{l}\text { Number of respiratory } \\
\text { consultations during } \\
\text { 12-month follow-up }\end{array}$} & & & \\
\hline & 0 & $162(59.1 \%)$ & $184(66.4 \%)$ \\
\hline & 1 & $59(21.5 \%)$ & $58(20.9 \%)$ \\
\hline & 2 & $27(9.9 \%)$ & $22(7.9 \%)$ \\
\hline & 3 & $17(6.2 \%)$ & $9(3.2 \%)$ \\
\hline & 4 & $3(1.1 \%)$ & 0 \\
\hline & 5 & $1(0.4 \%)$ & 0 \\
\hline & Missing & $5(1.8 \%)$ & $4(1.4 \%)$ \\
\hline $\begin{array}{l}\text { Mean total } \\
\text { consultations during } \\
\text { 12-month follow-up } \\
\text { (SD) (n) }\end{array}$ & & $9.05(7.53)(268)$ & $8.98(8.14)(273)$ \\
\hline \multirow[t]{3}{*}{$\begin{array}{l}\text { At least one } \\
\text { consultation during } \\
12 \text {-month follow-up }\end{array}$} & No & $21(7.7 \%)$ & $25(9.0 \%)$ \\
\hline & Yes & 247 (90.1\%) & $248(89.5 \%)$ \\
\hline & Missing & $6(2.2 \%)$ & $4(1.4 \%)$ \\
\hline
\end{tabular}

Centre, based at the University of Sydney. Stratifying variables for randomisation were MRC dyspnoea score (scores 1-3 and 4-5) and general practice recruitment site.

\section{Blinding}

Outcomes assessed by self-report obviated the need for researcher blinding. For the extraction and analysis of health service utilisation data, research staff were blinded to group assignment. All statistical analyses were performed blinded to group assignment.

\section{Statistical methods}

All randomised patients were considered eligible for inclusion in the analysis in accordance with the intention-to-treat analysis principle. In accordance with the provision specified in the statistical analysis plan, a negative binomial model was used for the analysis of data on consultation rates because of overdispersion that rendered the Poisson model inappropriate. The model included general practice as a fixed effect and accounted for additional variation due to repeat consultations by the same participant. The effect of clustering arising from couples being randomised together was explored by fitting the model using the method of generalised estimating equations. Comparisons between groups on continuous secondary endpoints were performed using a linear model that included general practice as a factor and the baseline value as a covariate (where applicable). Comparisons between groups on categorical secondary endpoints were performed using logistic regression with general practice fitted as a factor. The analyses performed on the primary and secondary endpoints were repeated adjusting for additional baseline covariates (eg, number of consultations in 12 months prior to randomisation, gender, comorbidities, smoking status, MRC dyspnoea score) as part of a sensitivity analysis. A mixed model for repeated measures was applied to the scale scores from patient-reported outcomes and included covariates for general practice, treatment allocation, timepoint, baseline and a timepoint-by-treatment allocation interaction. Survival analysis methods (including the log-rank test and proportional hazards
Table 3 Secondary analysis of respiratory consultations adjusting for other baseline covariates

\begin{tabular}{lll}
\hline $\begin{array}{l}\text { Covariates in negative } \\
\text { binomial model }\end{array}$ & $\begin{array}{l}\text { Relative rate adjusted for } \\
\text { covariate }(95 \% \mathrm{Cl})\end{array}$ & \\
\hline $\begin{array}{l}\text { Treatment group only } \\
\begin{array}{l}\text { GP site plus the following } \\
\text { covariate: }\end{array}\end{array}$ & $1.42(1.08$ to 1.87$), \mathrm{p}=0.0118$ & $\begin{array}{l}\text { P-value for } \\
\text { covariate listed }\end{array}$ \\
\hline $\begin{array}{l}\text { Respiratory consultations } \\
\text { from } 12 \text { months to baseline }\end{array}$ & 1.35 (1.04 to 1.74$), \mathrm{p}=0.0227$ & $<0.0001$ \\
\hline Pack-years & $1.40(1.07$ to 1.82$), \mathrm{p}=0.0125$ & 0.2513 \\
\hline Age & $1.40(1.07$ to 1.81$), \mathrm{p}=0.0128$ & 0.0122 \\
\hline FEV1 & $1.37(1.06$ to 1.77$), \mathrm{p}=0.0159$ & $<0.0001$ \\
\hline Gender & $1.40(1.08$ to 1.83$), \mathrm{p}=0.0115$ & 0.3145 \\
\hline Smoker & $1.39(1.07$ to 1.82$), \mathrm{p}=0.0142$ & 0.7077 \\
\hline MRC dyspnoea (1-2 vs $3-4)$ & 1.41 (1.08 to 1.83$), \mathrm{p}=0.0110$ & 0.0728 \\
\hline Cardiovascular comorbidity & $1.37(1.05$ to 1.78$), \mathrm{p}=0.0188$ & 0.0756 \\
\hline Respiratory comorbidity & $1.38(1.08$ to 1.78$), \mathrm{p}=0.0112$ & $<0.0001$ \\
\hline Psychiatric comorbidity & $1.40(1.08$ to 1.81$), \mathrm{p}=0.0100$ & 0.9965 \\
\hline Diabetes & $1.40(1.08$ to 1.83$), \mathrm{p}=0.0116$ & 0.4836 \\
\hline Other comorbidity & $1.41(1.08$ to 1.84$), \mathrm{p}=0.0103$ & 0.2033 \\
\hline GP, general practitioner. & & \\
\hline
\end{tabular}

regression) were used to compare randomised groups on time to first consultation for a respiratory symptom from baseline.

Costs of delivering the CHEST intervention were calculated to include: identification of the at-risk population, invitation processes, training to deliver the CHEST intervention, consultation time (assuming delivered by a practice nurse), spirometry equipment including laptop computer, and patient reminders. Total health service costs were derived by multiplying the resource used by the relevant MBS and PBS fee; these data included patient copayment contribution. Costs are reported as undiscounted cost for 2016. We calculated an incremental cost-effectiveness ratio (ICER) per additional respiratory consultation. We performed sensitivity analyses including the costs of spirometry equipment as this was not a core part of the intervention.

\section{RESULTS}

Between 29 May 2013 and 19 November 2015, we approached 2501 current and 2666 ex-smokers, and 112 with unclear quit status; 940 of these (17.8\%) responded. Of these, $623(66 \%)$ met our eligibility criteria and 551 (88\%) consented to be randomised (see figure 1).

Table 1 presents baseline data on the trial cohort. Patients who did not respond to the initial trial invitation were similar in terms of age (mean 65.7 years) and sex $(56.0 \%$ male) but were more likely to be current smokers (48.0\% vs $42.6 \%)$. There was a higher proportion of current smokers in the control than intervention group (46.6\% vs $38.7 \%$ ) but no other between-group imbalances. Three patients were diagnosed with lung cancer during the 12-month follow-up, two in the intervention group and one in the control group.

The primary outcome was determined for 542 participants (98.3\%); 12-month questionnaire data were available on 416 participants (intervention 212 (77\%); control 204 (74\%)). SYMPTOM questionnaires were completed for $88 \%$ of intervention and $66 \%$ of control consultations.

Table 2 presents data on total GP consultations and those for respiratory symptoms. On average, the overall cohort consulted their GP approximately nine times over the 12-month follow-up 
Table 4 HADS, cancer worry and AQoL-8D over time and between groups

\begin{tabular}{|c|c|c|c|c|c|c|c|c|c|c|c|c|}
\hline Month & Randomised group & $\mathrm{N}$ & Mean & SD & Min & $\operatorname{Max}$ & LS mean & $\begin{array}{l}\text { LS Mean } \\
\text { difference }\end{array}$ & $\begin{array}{l}\text { Lower } \\
95 \% \mathrm{CL}\end{array}$ & $\begin{array}{l}\text { Upper } \\
95 \% \text { CL }\end{array}$ & $\begin{array}{l}\text { P-value for } \\
\text { difference }\end{array}$ & $\begin{array}{l}\text { P-value for } \\
\text { difference rank } \\
\text { analysis }\end{array}$ \\
\hline \multicolumn{13}{|l|}{ Anxiety } \\
\hline 0 & Control & 268 & 5.6 & 4.1 & 0.0 & 21.0 & & & & & & \\
\hline 0 & Intervention & 269 & 5.7 & 3.9 & 0.0 & 21.0 & & & & & & \\
\hline 1 & Control & 223 & 5.3 & 4.2 & 0.0 & 18.0 & 5.5 & & & & & \\
\hline 1 & Intervention & 234 & 5.3 & 4.0 & 0.0 & 20.0 & 5.3 & -0.2 & -0.7 & 0.3 & 0.3954 & 0.6054 \\
\hline 12 & Control & 204 & 5.2 & 4.2 & 0.0 & 18.0 & 5.6 & & & & & \\
\hline 12 & Intervention & 212 & 5.3 & 4.1 & 0.0 & 19.0 & 5.4 & -0.1 & -0.6 & 0.4 & 0.6083 & 0.5179 \\
\hline \multicolumn{13}{|c|}{ Depression } \\
\hline 0 & Control & 268 & 4.4 & 3.8 & 0.0 & 20.0 & & & & & & \\
\hline 0 & Intervention & 269 & 4.1 & 3.4 & 0.0 & 19.0 & & & & & & \\
\hline 1 & Control & 223 & 4.3 & 4.1 & 0.0 & 21.0 & 4.2 & & & & & \\
\hline 1 & Intervention & 234 & 3.9 & 3.5 & 0.0 & 16.0 & 3.9 & -0.3 & -0.7 & 0.1 & 0.1557 & 0.1218 \\
\hline 12 & Control & 204 & 4.4 & 4.1 & 0.0 & 21.0 & 4.2 & & & & & \\
\hline 12 & Intervention & 212 & 3.9 & 3.5 & 0.0 & 19.0 & 4.0 & -0.2 & -0.7 & 0.2 & 0.3672 & 0.3344 \\
\hline \multicolumn{13}{|c|}{ Cancer worry } \\
\hline 0 & Control & 268 & 3.4 & 3.2 & 0.0 & 17.0 & & & & & & \\
\hline 0 & Intervention & 269 & 3.4 & 3.2 & 0.0 & 17.0 & & & & & & \\
\hline 1 & Control & 223 & 3.3 & 3.3 & 0.0 & 16.0 & 3.7 & & & & & \\
\hline 1 & Intervention & 234 & 3.2 & 3.1 & 0.0 & 18.0 & 3.5 & -0.2 & -0.7 & 0.2 & 0.3381 & 0.4166 \\
\hline 12 & Control & 204 & 2.9 & 3.0 & 0.0 & 16.0 & 3.5 & & & & & \\
\hline 12 & Intervention & 212 & 2.8 & 3.2 & 0.0 & 18.0 & 3.2 & -0.3 & -0.7 & 0.2 & 0.2436 & 0.1576 \\
\hline \multicolumn{13}{|c|}{ Quality of life } \\
\hline 0 & Control & 268 & 76.5 & 13.6 & 23.4 & 124.8 & & & & & & \\
\hline 0 & Intervention & 268 & 77.1 & 12.2 & 27.7 & 115.6 & & & & & & \\
\hline 1 & Control & 221 & 77.5 & 15.9 & 11.4 & 124.8 & 78.1 & & & & & \\
\hline 1 & Intervention & 234 & 79.6 & 14.2 & 31.2 & 124.8 & 79.3 & 1.2 & -0.9 & 3.2 & 0.2562 & 0.1915 \\
\hline 12 & Control & 203 & 77.2 & 14.5 & 20.6 & 124.8 & 78.1 & & & & & \\
\hline 12 & Intervention & 213 & 79.1 & 15.1 & 27.0 & 124.8 & 78.8 & 0.7 & -1.4 & 2.8 & 0.5111 & 0.5923 \\
\hline
\end{tabular}

AQoL, Assessment of Quality of Life; CL, confidence limit; HADS, Hospital Anxiety and Depression Scale; LS, least square; Max, maximum; Min, minimum.

period, but the majority did not consult at all about respiratory symptoms (intervention $59.5 \%$ vs control $66.4 \%$ ). In the negative binomial model, with trial group and practice site as covariates, there was a $40 \%$ relative increase in respiratory consultations in the intervention group: (adjusted rates (95\% CI) intervention 0.57 ( 0.47 to 0.70$)$, control 0.41 (0.32 to 0.52$)$, relative rate 1.40 (1.08 to 1.82$) ; p=0.0123)$. This effect remained after adjusting for additional baseline covariates (table 3). In the negative binomial model, with trial group and practice site as covariates, there was no difference between groups on total consultation rates: (adjusted rates $(95 \% \mathrm{CI})$, intervention 8.52 (7.63 to 9.52$)$, control 8.45 (7.51 to 9.50$)$, relative rate 1.01 (0.88 to 1.16$) ; \mathrm{p}=0.8998)$.

Table 4 presents the results of mixed model repeated measures analyses of HADS, cancer worry and AQoL-8D data. There were no statistically significant differences between trial groups in depression, general or cancer-specific anxiety, or quality of life. Table 5 shows that there were no significant differences between trial groups over time in perceived risk, self-efficacy to consult or knowledge of symptoms lung disease.

Table 6 presents the results on time from onset of respiratory symptom to GP consultation, for all consultations combined and for each serial consultation. Figure 2 presents the survival analysis curves for time to first respiratory consultation. In the survival analyses, there was no significant difference in time to first respiratory consultation (log-rank test : $\chi^{2} 1.5923$ (degrees of freedom (df) 1), $\mathrm{p}>\chi^{2} 0.207$ ) or time to present for all consultations (HR 0.827; 95\% CI 0.64 to 1.07 ; $\mathrm{p}=0.147$ ).

There were 46 chest X-rays ordered in the intervention group (mean 0.24 per person) and 50 in the control group (mean 0.25 per person). We were unable to identify accurately all referrals to respiratory specialists. The cost of the CHEST intervention (base case) was \$A207.77 (SD \$A99.22) per participant in the intervention group. Based on the adjusted respiratory consultation rate at 12 months, this equates to an ICER per additional respiratory consultation of \$A1289. In the sensitivity analysis, including the costs of spirometry equipment, the CHEST intervention cost \$A816.91 (SD \$A606.75) per participant in the intervention group, with an ICER of \$A5105 per additional respiratory consultation.

\section{DISCUSSION}

\section{Summary}

This is the largest trial yet to test the effect of a behavioural intervention to promote help-seeking in patients at increased risk of lung cancer. We demonstrated a statistically significant $40 \%$ relative increase in consultations about respiratory symptoms 


\begin{tabular}{|c|c|c|c|c|c|c|c|c|c|c|c|c|}
\hline Month & $\begin{array}{l}\text { Randomised } \\
\text { group }\end{array}$ & $\mathrm{N}$ & Mean & SD & Min & $\operatorname{Max}$ & LS mean & $\begin{array}{l}\text { LS mean } \\
\text { difference }\end{array}$ & $\begin{array}{l}\text { Lower } \\
95 \% \mathrm{CL}\end{array}$ & $\begin{array}{l}\text { Upper } \\
95 \% \mathrm{CL}\end{array}$ & $\begin{array}{l}\text { P-value for } \\
\text { difference }\end{array}$ & $\begin{array}{l}\text { P-value for } \\
\text { difference rank } \\
\text { analysis }\end{array}$ \\
\hline 0 & Control & 268 & 6.9 & 1.9 & 0.0 & 10.0 & & & & & & \\
\hline 0 & Intervention & 269 & 6.9 & 1.7 & 0.0 & 10.0 & & & & & & \\
\hline 12 & Control & 204 & 6.7 & 1.9 & 0.0 & 10.0 & 6.8 & & & & & \\
\hline 12 & Intervention & 212 & 6.7 & 1.9 & 0.0 & 10.0 & 6.8 & 0.1 & -0.2 & 0.3 & 0.6452 & 0.4904 \\
\hline \multicolumn{13}{|c|}{ Self-efficacy } \\
\hline 0 & Control & 268 & 85.0 & 24.2 & 0.0 & 110.0 & & & & & & \\
\hline 12 & Intervention & 212 & 94.5 & 17.5 & 0.0 & 110.0 & 94.1 & 2.4 & -1.0 & 5.9 & 0.1695 & 0.1683 \\
\hline \multicolumn{13}{|c|}{ Knowledge } \\
\hline 0 & Control & 268 & 9.0 & 5.4 & -8.0 & 19.0 & & & & & & \\
\hline 0 & Intervention & 269 & 8.7 & 5.9 & -10.0 & 19.0 & & & & & & \\
\hline 1 & Control & 223 & 9.4 & 5.4 & -9.0 & 19.0 & 9.5 & & & & & \\
\hline 1 & Intervention & 234 & 9.4 & 6.2 & -13.0 & 21.0 & 9.6 & 0.1 & -0.8 & 1.1 & 0.7769 & 0.4583 \\
\hline 12 & Control & 204 & 8.8 & 5.9 & -11.0 & 19.0 & 8.9 & & & & & \\
\hline 12 & Intervention & 212 & 9.7 & 6.1 & -8.0 & 19.0 & 9.9 & 1.0 & -0.0 & 2.0 & 0.0509 & 0.0271 \\
\hline
\end{tabular}

$\mathrm{CL}$, confidence limit; LS, least square; Max, maximum; Min, minimum.

in those receiving the intervention but no overall increase in consultation rates. There was a non-significant mean reduction of 14 days in time to first presentation with respiratory symptoms. There was no evidence of psychological harm from the intervention.

\section{Limitations}

This was designed as a phase II efficacy trial of a complex intervention. ${ }^{28}$ The primary outcome of respiratory consultation rates is based on the intervention logic model: by encouraging patients at increased risk of lung cancer to consult their GP when they develop respiratory symptoms, this would reduce the diagnostic delay of lung cancer and potentially result in the detection of earlier stage disease. Our primary outcome is, therefore, a suitable intermediate measure along this causal pathway. However, even in this population at

\begin{tabular}{lcl}
\hline Table 6 & \multicolumn{1}{c}{ Time from symptom onset to consultation } \\
\hline Characteristic & $\begin{array}{l}\text { Intervention } \\
(\mathrm{N}=274)\end{array}$ & $\begin{array}{l}\text { Control } \\
(\mathrm{N}=277)\end{array}$ \\
\hline $\begin{array}{l}\text { All consultations: mean days } \\
\text { (SD) (n) }\end{array}$ & $66.99(109.18)(107)$ & $76.32(102.31)(94)$ \\
\hline Median days (min-max) & $21(1-365)$ & $30(2-365)$ \\
Appointment 1: mean (SD) (n) & $62.5(102.26)(76)$ & $76.29(102.52)(70)$ \\
\hline Median days (min-max) & $21(2-365)$ & $30(2-365)$ \\
\hline Appointment 2: mean (SD) (n) & $71.22(119.75)(23)$ & $83.85(111.74)(20)$ \\
\hline Median days (min-max) & $14(3-365)$ & $30(2-365)$ \\
\hline Appointment 3: Mean (SD) (n) & $68(132.63)(7)$ & $39.25(37.85)(4)$ \\
\hline Median days (min-max) & $7(1-365)$ & $30(7-90)$ \\
\hline Appointment 4: mean (SD) (n) & $304(-)(1)$ & - \\
\hline Median days (min-max) & $304(304-304)$ & - \\
\hline
\end{tabular}

increased risk of lung cancer, during a 12-month follow-up period, only three participants $(0.54 \%)$ were diagnosed with lung cancer. It would require a substantially larger trial to be powered even to detect differences in time to diagnosis of lung cancer, let alone in clinical outcomes such as lung cancer stage or mortality. The control group received spirometry and a brief discussion about lung health. This was intended as an attention control but could potentially have also increased consultation rates for respiratory symptoms. There was also a chance imbalance between groups, with a higher proportion of current smokers in the control group. Both of these limitations could have reduced the estimated effect size of the CHEST intervention. We achieved a very low attrition rate for the primary outcome (98.3\%), but we had greater loss-to-follow-up for the

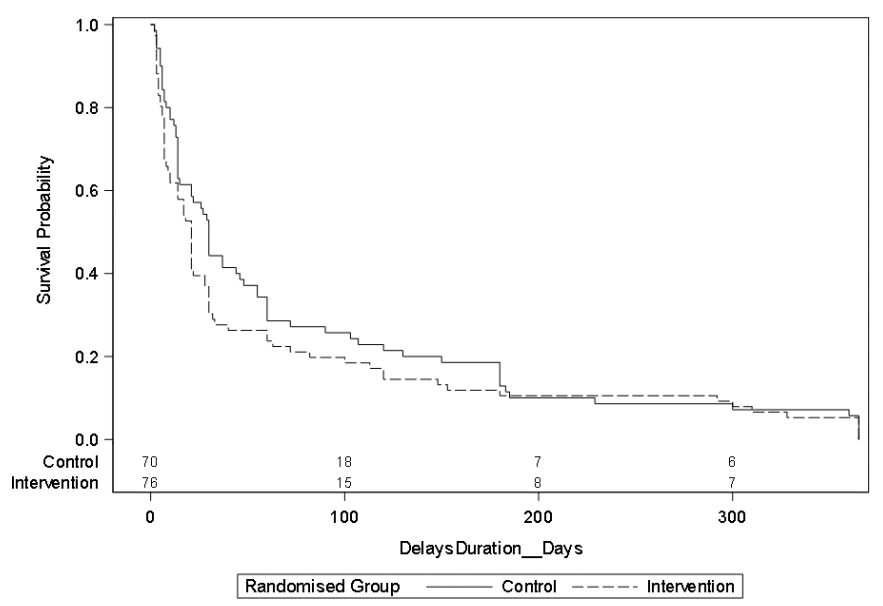

Figure 2 Survival curve for time from symptom onset to first consultation. 
patient-reported outcomes. In particular, there was greater attrition for responses to the SYMPTOM questionnaire in the control group. This might have biased our estimates of the effect of the intervention on time to GP consultation but it is difficult to know in which direction.

\section{Generalisability}

We recruited patients from general practices in two large Australian cities and from suburbs with a range of socioeconomic deprivation. Patients at increased risk of lung cancer are a 'hard-to-reach' group due to smoking stigma and socioeconomic deprivation. The response rate to the mailed invitation into the trial was $18 \%$ of whom only $66 \%$ were eligible. Our final accrual rate was $10.6 \%$; while participants had a similar age and sex distribution to non-responders, there was a higher proportion of ex-smokers in the trial (60\% vs 51\% in the invited population). It is possible that there was a selection bias towards those with less severe respiratory disease given the low rate of baseline respiratory consultations and lung function results. It is difficult to know in which direction this bias might affect our estimate of the effect size of the CHEST intervention. Current smokers may have greater barriers to consulting and therefore we might have seen a larger effect size in a less biased sample. Alternatively, those with more severe respiratory disease may be more frequent consulters at baseline, thereby reducing any potential effect on consultation rates.

\section{Interpretation}

Previous research in England found that patients at increased risk of lung cancer commonly have symptoms associated with lung cancer but many do not seek help about these symptoms. ${ }^{11} 34$ Smokers in particular are less likely than non-smokers to consult their GP when they develop respiratory symptoms. ${ }^{16}$ Non-consulters have higher tolerance for their symptoms, are more likely to self-manage and have greater concern about wasting their GP's time. ${ }^{11}$ Qualitative research with GPs has questioned the value of mass media symptom awareness campaigns due to concerns about overwhelming the health system. ${ }^{35}$ Together, these findings have led to calls for targeted interventions in primary care to improve symptom recognition and empower help-seeking in patients at increased risk of lung cancer. ${ }^{1635}$

Our parallel qualitative evaluation of the CHEST trial confirmed the theoretical underpinning of the intervention: we found evidence of reduction in stigma and guilt, increase in salience and personal relevance of symptoms and sanctioning of help-seeking, ${ }^{15}$ which translated into increased respiratory consultations. Of interest, in the trial we found no difference in our quantitative measures of knowledge, self-efficacy to consult, risk perception or measures of general and cancer-specific anxiety. We measured anxiety as a potential harm of the intervention. The theoretical models underpinning the CHEST intervention did not suggest we needed to create anxiety to have an effect; indeed, fear of cancer can be a barrier to help-seeking. ${ }^{10}$ The CHEST intervention did not alter overall consultation rates but had a specific effect on help-seeking for respiratory symptoms. Although it prompted more respiratory consultations, there was only a small reduction in the duration of symptoms before seeking help; an average of 14 days earlier for the first consultation and 9 days for all respiratory consultations. Participants in the intervention group took an average of 2 months from symptom onset to consult about a new respiratory symptom. This size of effect is unlikely to be of clinical significance. The intervention made it more likely that someone would present with respiratory symptoms, but further consideration is required on how to prompt even earlier presentation with these symptoms. It may be that additional interventions aimed at the GP are required. Patients with lung cancer often have multiple GP visits about respiratory symptoms before referral to a specialist for definitive diagnosis. ${ }^{36}$ By highlighting that these patients are at increased risk of lung cancer, they could potentially be investigated sooner by their GP and reduce the overall diagnostic interval. $^{37}$

The CHEST intervention cost \$A1289 per additional respiratory consultation. In the absence of trial data with sufficient numbers of lung cancer cases, it is difficult to estimate the cost per lung case detected. If we assume that $3 \%$ of these consultations led to a diagnosis of lung cancer, ${ }^{38}$ this would equate to approximately \$A42500 per case detected.

Significant uncertainty therefore remains about the best strategies to promote earlier detection of lung cancer. The US Preventive Services Taskforce has recommended low-dose CT screening for adults aged 55 to 80 years with at least a 30 packyear smoking history. ${ }^{39}$ Other countries are still considering the evidence to inform national policy. In Australia, the cost-effectiveness of lung cancer CT screening is estimated at \$A233000 per quality-adjusted life-year gained, making it less likely to be implemented in the near future. ${ }^{21}$ There are other limitations of focusing on low-dose CT screening as the main strategy for early detection of lung cancer. Low-dose CT is more effective at detecting parenchymal lung tumours and can miss small endobronchial cancers ${ }^{40}$ which are common among smokers and can potentially produce early symptoms. Interval lung cancers occur even with annual CT screening and will present symptomatically at a more advanced stage. ${ }^{41}$ Even within the context of national cancer screening programmes for breast and bowel cancer, the majority of these cancers are not detected via screening, due to low participation rates and interval cancers. ${ }^{42}$

A key implementation challenge for CT screening is the identification of the screening population. ${ }^{22}$ The findings of the CHEST Australia trial should perhaps be considered in the broader context of respiratory disease management in primary care including lung cancer and COPD. International guidelines currently do not recommend screening for COPD, but instead suggest a case-finding approach in patients at risk of the condition who have respiratory symptoms. ${ }^{43}$ The CHEST intervention could therefore be a way to identify patients at increased risk of either lung cancer or COPD and include spirometry as part of a respiratory health consultation. In those at very high risk of lung cancer (eg, more than 30 pack-years smoking history), low-dose CT screening would be recommended in some countries. For those at moderate risk of lung cancer, the behavioural CHEST intervention could raise patient awareness of respiratory symptoms, reduce stigma and promote help-seeking. This could potentially improve the management of COPD and prompt earlier assessment by their GP for lung cancer. The CHEST intervention is a relatively low-cost option which might have broader implications for improving the management of respiratory symptoms, and serious lung disease, in primary care.

\section{Author affiliations}

${ }^{1}$ Department of General Practice and Centre for Cancer Research, University of Melbourne, Melbourne, Victoria, Australia

${ }^{2}$ Department of General Practice, The Medical School, University of Western Australia, Perth, Australia

${ }^{3}$ The Primary Care Unit, Public Health and Primary Care, University of Cambridge, Cambridge, UK

${ }^{4}$ NHMRC Clinical Trials Centre, University of Sydney, Sydney, New South Wales, Australia

${ }^{5}$ Centre for Health Economics Research and Evaluation, University of Technology 
Sydney, Sydney, New South Wales, Australia

${ }^{6}$ Department of General Practice, Monash University, Melbourne, Victoria, Australia ${ }^{7}$ School of Nursing and Midwifery, Edith Cowan University, Perth, Western Australia, Australia

${ }^{8}$ Royal Prince Alfred Hospital, Newtown, New South Wales, Australia

${ }^{9}$ Central Clinical School, University of Sydney, Sydney, New South Wales, Australia

${ }^{10}$ The Centre of Academic Primary Care, University of Aberdeen, Aberdeen, UK

Acknowledgements We thank all the trial participants and general practitioners who were involved in this trial.

Contributors JDE, PM, FMW, AM, SG, DM and DJB contributed to the design of the trial and obtained funding for the trial. JDE, SRM, EH and YK contributed to the implementation of the trial protocol and acquisition of the data. AM led the statistical analyses and SG the health economic analyses. All authors contributed to the interpretation of the analyses. All authors contributed to the drafting of the manuscript and have approved the final version. JDE is guarantor.

Funding This trial was funded by the NHMRC (grant ID 1064121). It was supported by the Cancer Australia Primary Care Collaborative Cancer Clinical Trials Group (PC4). JDE is supported by an NHMRC Practitioner Fellowship. FMW was supported by a Clinician Scientist award (RG 68235) from the National Institute for Health Research.

\section{Competing interests None declared.}

Patient consent for publication Not required.

Ethics approval University of Western Australia Human Research Ethics Committee (RA/4/1/6018) and University of Melbourne (1441433).

Provenance and peer review Not commissioned; externally peer reviewed.

Open access This is an open access article distributed in accordance with the Creative Commons Attribution Non Commercial (CC BY-NC 4.0) license, which permits others to distribute, remix, adapt, build upon this work non-commercially, and license their derivative works on different terms, provided the original work is properly cited, appropriate credit is given, any changes made indicated, and the use is non-commercial. See: http://creativecommons.org/licenses/by-nc/4.0/.

\section{REFERENCES}

1 Internatonal Agency for Research on Cancer. Lung cancer estimated incidence, mortality and prevalence worldwide 2012: Internatonal Agency for Research on Cancer, 2018.

2 Cancer Australia. Lung cancer in Australia. Sydney: Cancer Australia, 2018.

3 Cancer Australia. Lung cancer survival statistics. London: Cancer Research UK, 2018.

4 . National Cancer Control Indicators. Sydney: Cancer Australia, 2018.

5 Olsson JK, Schultz EM, Gould MK. Timeliness of care in patients with lung cancer: a systematic review. Thorax 2009;64:749-56.

6 Neal RD, Tharmanathan P, France B, et al. Is increased time to diagnosis and treatment in symptomatic cancer associated with poorer outcomes? Systematic review. $\mathrm{Br}$ J Cancer 2015;112:S92-S107.

7 Rubin G, Berendsen A, Crawford SM, et al. The expanding role of primary care in cancer control. Lancet Oncol 2015;16:1231-72.

8 Scott SE, Walter FM, Webster A, et al. The model of pathways to treatment: conceptualization and integration with existing theory. $\mathrm{Br} J$ Health Psychol 2013:18:45-65

9 Walter F, Webster A, Scott S, et al. The Andersen Model of Total Patient Delay: a systematic review of its application in cancer diagnosis. J Health Serv Res Policy 2012;17:110-8

10 Macleod U, Mitchell ED, Burgess C, et al. Risk factors for delayed presentation and referral of symptomatic cancer: evidence for common cancers. $\mathrm{Br} J \mathrm{Cancer}$ 2009;101:S92-S101

11 Wagland $\mathrm{R}$, Brindle $\mathrm{L}$, Ewings $\mathrm{S}$, et al. Promoting help-seeking in response to symptoms amongst primary care patients at high risk of lung cancer: a mixed method study. PLoS One 2016:11:e0165677.

12 Emery JD, Walter FM, Gray V, et al. Diagnosing cancer in the bush: a mixed-methods study of symptom appraisal and help-seeking behaviour in people with cancer from rural Western Australia. Fam Pract 2013:30:294-301.

13 MacLean A, Hunt K, Smith S, et al. Does gender matter? An analysis of men's and women's accounts of responding to symptoms of lung cancer. Soc Sci Med 2017;191:134-42

14 Scott N, Crane M, Lafontaine M, et al. Stigma as a barrier to diagnosis of lung cancer: patient and general practitioner perspectives. Prim Health Care Res Dev 2015:16:618-22.

15 Murray SR, Kutzer Y, Habgood E, et al. Reducing barriers to consulting a general practitioner in patients at increased risk of lung cancer: a qualitative evaluation of the CHEST Australia intervention. Fam Pract 2017;34:740-6.

16 Walabyeki J, Adamson J, Buckley HL, et al. Experience of, awareness of and helpseeking for potential cancer symptoms in smokers and non-smokers: A cross-sectional study. PLoS One 2017;12:e0183647.
17 Emery JD, Gray V, Walter FM, et al. The Improving Rural Cancer Outcomes Trial: a cluster-randomised controlled trial of a complex intervention to reduce time to diagnosis in rural cancer patients in Western Australia. Br J Cancer 2017:117:1459-69.

18 Hall SE, Holman CD, Threlfall T, et al. Lung cancer: an exploration of patient and general practitioner perspectives on the realities of care in rural Western Australia. Aust J Rural Health 2008;16:355-62.

19 Henschke $\mathrm{Cl}$, Yankelevitz DF, Yip R, et al. Lung cancers diagnosed at annual CT screening: volume doubling times. Radiology 2012;263:578-83.

20 Aberle DR, Adams AM, Berg CD, et al. Reduced lung-cancer mortality with low-dose computed tomographic screening. N Engl J Med 2011;365:395-409.

21 Wade S, Weber M, Caruana M, et al. Estimating the cost-effectiveness of lung cancer screening with low-dose computed tomography for high-risk smokers in Australia. J Thorac Oncol 2018;13:1094-105.

22 Manners D, Emery J, Brims FJ, et al. Lung cancer screening - practical challenges of confining participation to those who might benefit. Aust N Z J Public Health 2016;40:205-6.

23 Jett JR, Peek LJ, Fredericks L, et al. Audit of the autoantibody test, EarlyCDT@-lung, in 1600 patients: an evaluation of its performance in routine clinical practice. Lung Cancer 2014;83:51-5.

24 Ironmonger $\mathrm{L}$, Ohuma $\mathrm{E}$, Ormiston-Smith $\mathrm{N}$, et al. An evaluation of the impact of large-scale interventions to raise public awareness of a lung cancer symptom. $\mathrm{Br} J$ Cancer 2015:112:207-16.

25 Smith S, Fielding S, Murchie P, et al. Reducing the time before consulting with symptoms of lung cancer: a randomised controlled trial in primary care. $\mathrm{Br} J \mathrm{Gen}$ Pract 2013;63:e47-e54.

26 Murray SR, Murchie P, Campbell N, et al. Protocol for the CHEST Australia Trial: a phase II randomised controlled trial of an intervention to reduce time-to-consult with symptoms of lung cancer. BMJ Open 2015;5:e008046.

27 Smith SM, Murchie P, Devereux G, et al. Developing a complex intervention to reduce time to presentation with symptoms of lung cancer. Br J Gen Pract 2012;62:e605-e615

28 Craig P, Dieppe P, Macintyre S, et al. Developing and evaluating complex interventions: the new Medical Research Council guidance. BMJ 2008;337:a1655.

29 Bestall JC, Paul EA, Garrod R, et al. Usefulness of the Medical Research Council (MRC) Dyspnoea Scale as a measure of disability in patients with chronic obstructive pulmonary disease. Thorax 1999:54:581-6.

30 Walter FM, Rubin G, Bankhead C, et al. Symptoms and other factors associated with time to diagnosis and stage of lung cancer: a prospective cohort study. $\mathrm{Br} J$ Cancer 2015;112 Suppl 1 S6-S13.

31 Zigmond AS, Snaith RP. The hospital anxiety and depression scale. Acta Psychiatr Scand 1983:67:361-70.

32 Lerman C, Trock B, Rimer BK, et al. Psychological and behavioral implications of abnormal mammograms. Ann Intern Med 1991;114:657-61.

33 Richardson J, lezzi A, Khan MA, et al. Validity and reliability of the Assessment of Quality of Life (AQoL)-8D multi-attribute utility instrument. Patient 2014;7:85-96.

34 Birt L, Hall N, Emery J, et al. Responding to symptoms suggestive of lung cancer: a qualitative interview study. BMJ Open Respir Res 2014:1:e000067.

35 Wagland R, Brindle L, James E, et al. Facilitating early diagnosis of lung cancer amongst primary care patients: The views of GPs. Eur J Cancer Care 2017:26:e12704.

36 Lyratzopoulos G, Neal RD, Barbiere JM, et al. Variation in number of general practitioner consultations before hospital referral for cancer: findings from the 2010 National Cancer Patient Experience Survey in England. Lancet Oncol 2012:13:353-65.

37 Neal RD, Barham A, Bongard E, et al. Immediate chest X-ray for patients at risk of lung cancer presenting in primary care: randomised controlled feasibility trial. $\mathrm{Br} J$ Cancer 2017;116:293-302.

38 NICE Guideline. Suspected cancer: recognition and referral. London: National Institute for Health and Care Excellence, 2015.

39 Moyer VA. Screening for lung cancer: u.s. preventive services task force recommendation statement. Ann Intern Med 2014;160:330-338-8.

40 Chu ZG, Yang ZG, Shao H, et al. Small peripheral lung adenocarcinoma: CT and histopathologic characteristics and prognostic implications. Cancer Imaging 2011:11:237-46

41 Horeweg N, Scholten ET, de Jong PA, et al. Detection of lung cancer through low-dose CT screening (NELSON): a prespecified analysis of screening test performance and interval cancers. Lancet Oncol 2014;15:1342-50.

42 Elliss-Brookes L, McPhail S, Ives A, et al. Routes to diagnosis for cancer determining the patient journey using multiple routine data sets. $\mathrm{Br} J$ Cancer 2012:107:1220-6.

43 Siu AL, Bibbins-Domingo K, Grossman DC, et al. Screening for chronic obstructive pulmonary disease: us preventive services task force recommendation statement. JAMA 2016:315:1372-7.

44 Yang IA, Brown JL, George J, et al. COPD-X Australian and New Zealand guidelines for the diagnosis and management of chronic obstructive pulmonary disease: 2017 update. Med J Aust 2017;207:436-42. 